\title{
Research on the Novel Financial Affairs Evaluation Methodology based on Entropy Value Method and Gray Theory
}

\author{
Lihong Yang ${ }^{1}$ \\ ${ }^{1}$ Pingxiang University, \\ Pingxiang,Jiangxi,337000 China
}

\author{
Jihua Liu ${ }^{2}$ \\ ${ }^{2}$ Jiangxi Vocational College Of \\ Industry\&Engineering,
}

Pingxiang,Jiangxi,337000 China

\begin{abstract}
In this paper, we research on the novel financial affairs evaluation methodology based on entropy value method and gray theory. Separate analysis of any financial indicators which are difficult to evaluate comprehensively the financial position and operating results of an enterprise. Grey fuzzy comprehensive evaluation can be understood as the known information under the premise of not fully judge things or phenomena with fuzzy factors. Our proposed approach could solve the existing drawbacks well. In the future, more corresponding research will be finalized.
\end{abstract}

Keywords: Financial Affairs Evaluation; Entropy Value; Gray Theory; Statistical Approach.

\section{Introduction}

Financial comprehensive evaluation on enterprise financial report reflects the financial indicators as the main basis, to evaluate the enterprise financial position and operating results, financial report users to provide decision support for aspects of financial information. Separate any financial index analysis and evaluation, it is difficult to fully disclose the enterprise financial position and operating results. Will only reflect the enterprise operation ability, solvency and profitability of financial index into an organic whole, and take the appropriate method synthetically, evaluates the advantages and disadvantages of the economic benefits of the enterprise and judgment which can grasp accurately, therefore, the enterprise financial information, and make scientific and rational analysis, relationship to the investors to evade the investment risk reasonably and effective guarantee investment income, at the same time also is the need of enterprises for effective self-diagnosis. Separate analysis of any financial indicators, are difficult to evaluate comprehensively the financial position and operating results of an enterprise. To the enterprise's financial position and operating results have the overall evaluations. Because of the order of magnitude of the financial evaluation indicators and can have different dimensions, and property is different also. So, in order to eliminate not commensurability between each index and the index trend of unified requirements, each financial index should be divided into efficiency, cost, fixed type and interval four conditions that respectively to finalize the standardization. With the continuous development of market economy in our country, the relationship between each enterprise will present intricate[1-3]. Companies for the development of scale, operating performance, profitability, the value of the shares, and many other reflect company's comprehensive strength index which has become the focus of many individual and collective.

In multivariate statistical analysis, factor analysis is a kind of very effective dimensionality of information extraction techniques, factor analysis is a kind of the complicated relationship between variables comes down to a few comprehensive factor of multilateral statistical analysis method, factor analysis is on the premise 
of try to reduce the loss of information, extracted from several indicators were not associated with a small number of indicators, and then according to the contribution rate to weight, and then calculate the comprehensive score [4]. Grey fuzzy comprehensive evaluation can be understood as the known information under the premise of not fully judge things or phenomena with fuzzy factors which is a method that grey means less inadequate quantity and the concept of fuzzy information refers to a concept is not clear factors in the evaluation information can be understood as a concept of qualitative information. The operating performance of listed companies can reflect through a series of financial indicators. But the financial index can only reflect the company's business activities respectively some time in some way. And corporate investors and managers often need to make comprehensive evaluation to enterprise's financial situation, as the basis of investment and management decisions. Usually, using the index system of comprehensive evaluation of business performance, the various indicators of empowerment problem always stuck around the evaluators. Most current operating performance comprehensive evaluation method is a very prominent problem, namely the subjective empowerment. On the one hand, this will lead to a too high or too low estimate of a certain factors and evaluation cannot fully reflect the real situation of listed companies. In the figure one, we show the combination model of entropy value method and gray theory.

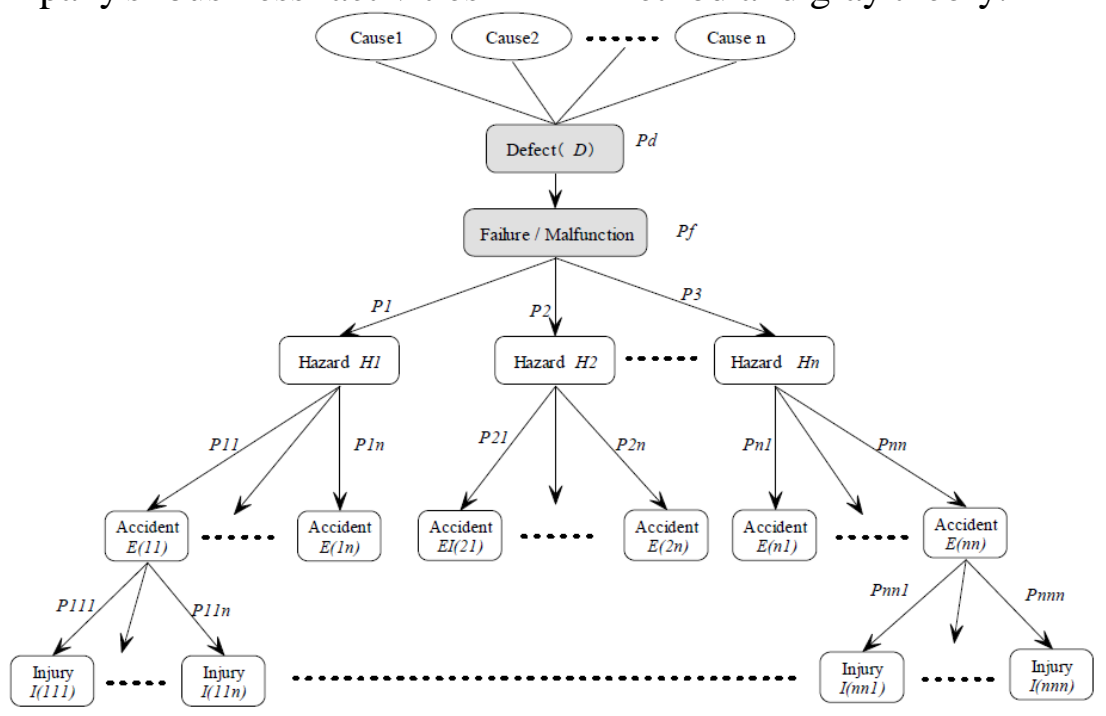

Fig. 1The Combination Model of Entropy Value Method and Gray Theory

In this paper, we research on the novel financial affairs evaluation methodology based on entropy value method and gray theory. Efficacy coefficient method is according to the principle of multi-objective programming, the need to evaluate each index respectively, the comparison of the respective standard, and according to the weight of each index. Through the efficacy function into measurable evaluation scores, aggregation on the indicators of monomial index score. In the following sections, we will discuss the proposed methodology in detail.

\section{The Proposed Methodology}

The Concepts of Grey Theory. Grey fuzzy comprehensive evaluation is under the condition of insufficient information of evaluation in the process and result of comprehensive evaluation on how much information should have the corresponding parameter descriptions at different levels of adequate information on the same issue the results will be different or the results of the credible degree. After the model selected, must pass through test to determine whether it is 
reasonable, can only be used to forecast the proven model with. The precision of the grey model test generally has three methods: residual size test, correlation test and posterior deviation test. Gray fuzzy comprehensive evaluation assessment and quantitative analysis and qualitative analysis of the combination of evaluation methods. The following formula defines this feature.

$$
D_{i j}=1 / n \sum_{k=1}\left(C_{i k}-C_{j k}\right)
$$

When things to make use of multiple indexes comprehensive evaluation, to a certain index, if the value of the individuals do not have too big difference, then the indexes in the comprehensive analysis of the role of small. Conversely, if for some indicators, the value of each individual has a lot of volatility, namely the index of discrete degree is very big, this index has important influence on comprehensive analysis, so can make use of gray theory as a basis to determine the index weight.

$$
B_{i j}=\left[\left(a_{1}, v_{1}\right),\left(a_{2}, v_{2}\right),\left(a_{3}, v_{3}\right), \ldots,\left(a_{m}, v_{m}\right)\right]
$$

The analysis to the problem of multiple indexes, can use all kinds of different methods, if the result of a variety of methods to get consistent with each other, have strong correlation, the results of different methods can be considered, and the different methods to adopt the method of weighted sum and the final result which is shown in the following formula three.

$$
\text { 早 }=\left[\left(d_{j}\left(1-v_{d j}\right), d_{j}, d_{j}\left(1+v_{d j}\right)\right)\right]
$$

The gray method of calculation with the indicators of companies in the same parameter values of the proportion of the total, so calculation cannot standardized, but against the original data. But due to the negative data, which is unfavorable for the final calculation, so before calculating the data is nonnegative. At the same time, because the entropy value is calculated using logarithmic to avoid the logarithmic nonsense, can the data translation again.

The Core Techniques of Entropy Value Method. In information theory, entropy is to reflect the degree of a system disorder. The smaller the information entropy, the system the greater the degree of disorder will be obtained. In terms of enterprise financial evaluation, if a financial indicators for different enterprises with small level differences, suggesting that the financial index to distinguish and evaluate the role of enterprise financial situation and also small, and the corresponding information entropy; If a financial indicators for different enterprises its difference degree is bigger, it shows that the financial index to distinguish and evaluate the role of enterprise financial situation and is bigger also, and the corresponding information entropy is smaller. That is to say, the size of the financial index difference degree which reflects the indexes in the comprehensive evaluation index system of financial evaluation of the status, and the size of the degree of financial index difference completely can use the "entropy" reverse measure. The formula four expresses this.

$$
H(x)=-\sum P\left(x_{i}\right) \ln P\left(x_{i}\right)
$$

Comparing the entropy value method and comprehensive index method of the evaluation results, entropy value method can be found that give accounts receivable turnover, inventory turnover, current ratio, debt cash support the weight of evaluation index is bigger and this is obviously different from the comprehensive index method. The information is reflected from the following figure. 


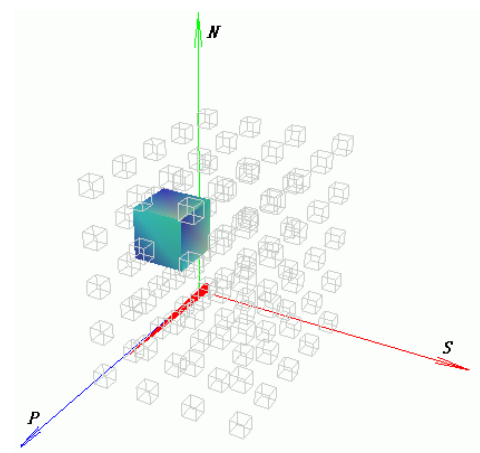

Fig. 2The Information Entropy Space and Coordinate System

The current comprehensive evaluation method is usually adopted subjective empowerment. When the index is large, the subjective empowerment often leads to too high or too low estimate of a certain factors, so that the evaluation cannot fully reflect the real situation of the listed company. In addition, subjective values and the related weight once established, it rarely changes, but evaluators selected investigation object is the random fluctuation, it also influenced the comprehensive evaluation of objectivity. To the most of the evaluation indexes in the comprehensive evaluation, is the greater the numerical better positive indicator. Because each indicator shows that the evaluation content of different, they may also have different dimension and order of magnitude. Therefore, the need for dimensionless processing and the index practical value into value in order to solve of multiple indexes is necessary. Reflect the status of the listed company financial aspects of the different indicators tend to have different dimensions and dimensional units. In order to eliminate not the commensurability of the resulting indexes, we use method, the effect of dimensionless processing for evaluation index.

$$
H(x)=\left(h_{i 1}, h_{i 2}, h_{i 3}, \ldots, h_{i m}\right)
$$

In information theory, entropy is a measure of uncertainty. Factors that affect the company comprehensive strength is more, to effectively will clear these factors comprehensive analysis and find out the relationship between these factors, is the complicated system engineering.
According to the characteristics of entropy, we can be judged by calculating entropy the randomness and the entropy value can also be used to judge the discrete degree of some indicators.

The Combination and the Applications of the Theories. Financial comprehensive evaluation on enterprise financial report reflects the financial indicators as the main basis, to evaluate the enterprise financial position and operating results, financial report users to provide decision support for aspects of financial information. Separate any financial index analysis and evaluation, it is difficult to fully disclose the enterprise financial position and operating results. Will only reflect the enterprise operation ability, solvency and profitability of financial index into an organic whole, and take the appropriate method synthetically, evaluates the advantages and disadvantages of the economic benefits of the enterprise and judgment. Therefore, in the financial comprehensive evaluation, asset-liability ratio index in reflecting the enterprise's solvency without liability cash support more comparable. In the figure three, we show the measurement result and related parameters.

\begin{tabular}{|c|c|c|c|}
\hline $\begin{array}{c}\text { first-level } \\
\text { index }\end{array}$ & $\begin{array}{c}\text { Order } \\
\text { number }\end{array}$ & second-level index & $\begin{array}{c}\text { Order } \\
\text { number }\end{array}$ \\
\hline \multirow{4}{*}{$\begin{array}{l}\text { Technology } \\
\text { Assessment }\end{array}$} & \multirow{4}{*}{$B_{1}$} & $\begin{array}{c}\text { Equipment } \\
\text { advanced }\end{array}$ & $C_{11}$ \\
\hline & & $\begin{array}{l}\text { Equipment } \\
\text { economy }\end{array}$ & $C_{12}$ \\
\hline & & $\begin{array}{c}\text { Equipment } \\
\text { applicability }\end{array}$ & $C_{13}$ \\
\hline & & $\begin{array}{l}\text { Integrate } \\
\text { reliability }\end{array}$ & $C_{14}$ \\
\hline \multirow{3}{*}{$\begin{array}{c}\text { Economic } \\
\text { Assessment }\end{array}$} & \multirow[t]{3}{*}{$B_{2}$} & $\begin{array}{c}\text { Internal rate of } \\
\text { return }\end{array}$ & $C_{21}$ \\
\hline & & Rate of investment & $C_{22}$ \\
\hline & & Asset-liability ratio & $C_{23}$ \\
\hline \multirow{3}{*}{$\begin{array}{c}\text { Environment } \\
\text { Assessment }\end{array}$} & \multirow{3}{*}{$B_{3}$} & Noise & $C_{31}$ \\
\hline & & $\begin{array}{c}\text { Electromagnetic } \\
\text { radiation }\end{array}$ & $C_{32}$ \\
\hline & & Hydrology & $C_{33}$ \\
\hline \multirow{3}{*}{ Social impact } & \multirow{3}{*}{$B_{4}$} & Employment & $C_{41}$ \\
\hline & & $\begin{array}{l}\text { Quality of } \\
\text { residential } \\
\text { electricity }\end{array}$ & $C_{42}$ \\
\hline & & $\begin{array}{l}\text { Quality of } \\
\text { industrial } \\
\text { electricity }\end{array}$ & $C_{43}$ \\
\hline
\end{tabular}

Fig. 3The Measurement Result and Related Parameters 


\section{Conclusion}

In this paper, we research on the novel financial affairs evaluation methodology based on entropy value method and gray theory. Financial evaluation is based on enterprise financial reports reflect the financial indicators as the main basis, to evaluate the financial position and operating results of an enterprise and analysis to reflect the enterprise in the process of operating the pros and cons, financial situation and development trend to improve enterprise financial work and optimizing the economic decision provides important financial information. Our proposed combined methodology will enhance the current measurement standard and help the manager to make correct decision.

\section{References}

[1] Vanuytrecht, Raes E $\times$, Willems D, et al. Global sensitivity analysis of yield output from the water productivity model[J]. Environmental Modelling \& Software, 2014, 51(1):323-332.

[2] Jin H J, Huang J, Huang C, et al. Evaluation Research on the Water Environment Quality of Niyang River Basin-Based on the Fuzzy Comprehensive Evaluation Method[J].

[3] Russo F, Bella S D, Bonnici V, et al. A knowledge base for the discovery of function, diagnostic potential and drug effects on cellular and extracellular miRNAs.[J]. Bmc Genomics, 2014, 15.

[4] Nimon K, Zigarmi D. The Work Cognition Inventory: Initial Evidence of Construct Validity for the Revised Form[J]. Journal of Career Assessment, 2014, 22(1):7-35. 